\title{
Optimized Alkaline Pretreatment Technology of Rice Straw for Ethanol Production
}

\author{
Yang LIU ${ }^{1, a^{*}}$, Zhongping QIU ${ }^{2, b}$ and Guichen WANG ${ }^{3, a}$ \\ ${ }^{1}$ Faculty of Geosciences and Environmental Engineering, Southwest Jiaotong University \\ ${ }^{2}$ School of Life Science and Engineering, Southwest Jiaotong University \\ ${ }^{3}$ Faculty of Geosciences and Environmental Engineering, Southwest Jiaotong University \\ aliuyang2010@home.swjtu.edu.cn, bzpqiu@163.com, cwangguichen@ home.swjtu.edu.cn
}

Keywords: Ethanol, Pretreatment, Alkaline, Rice Straw

Abstract. As a renewable energy, ethanol from lignocellulosic biomass has developed technologically in many ways. Effective pretreatment can enhance the enzymatic saccharification of cellulose by removing lignin and hemicellulose from raw material. Different alkaline pretreatment technologies were studied to find more effective and economical pretreatment of rice straw for ethanol production. Results showed that heated ammonia pretreatment was more effectively to remove lignin than hemicellulose. Combination of microwaves and heated ammonia enhanced the removal of lignin and enzymatic saccharification. Besides of lignin and hemicellulose, lime pretreatment removed cellulose as well, that decreased the enzymatic saccharification. Take enzymatic saccharification and weight loss into concern, $2 \% \mathrm{NaOH}$ pretreatment at $100^{\circ} \mathrm{C}$ is the most effective alkaline pretreatment technology of rice straw for ethanol production..

\section{Introduction}

Ethanol is a renewable, bio-based oxygenated fuel[1]. Developing ethanol as fuel will require developing lignocellulosic biomass as a feedstock because of its abundance and low cost[2,3]. However, the transformation from cellulose of straw to ethanol by microbes is rather complicated[4,5]. Since the protection of hemicellulose and lignin, the rate of enzymatic hydrolysis of cellulose is very low when cellulose is enzymatic hydrolyzed directly [6,7]. Therefore, it is necessary to pretreat the cellulose before hydrolysis by physical, chemical or biological technology[8,9]. The research of effective and low-cost pretreatment technology has been always attractive for years [10]. Acids were adopted in pretreatment popularly [11,12], however, it brought high load to the environment because it is rather difficult to process naturally. Furthermore, acid pretreatment eroded the facilities and brought undesirable by-products[13]. At the same time, alkaline materials attracted more attention recent years, for its lower cost and less environmental disturbances[14,15].

\section{Materials and Methods}

Few economical alkaline chemicals, such as ammonia, lime and $\mathrm{NaOH}$, were adopted in varied dosages to pretreat the rice straw in this research. Then the removal rates of lignin and hemicellulose of raw materials, the weight loss of raw materials and the enzymatic saccharification of residue of different pretreatment technologies were analyzed. Finally, the alkaline pretreatment technology of rice straw for ethanol production was optimized.

Materials. Rice straw from suburbs of Chengdu city was smashed and 20 mesh sieved, then was air-dried to constant weight at $60^{\circ} \mathrm{C}[16]$.

Buffer solutions included neutral detergent( $3 \%$ Sodium lauryl sulfate), $2 \mathrm{~mol} / \mathrm{L} \mathrm{HCl}, 72 \% \mathrm{H} 2 \mathrm{SO} 4$ and 0.05mol/L Citric acid buffer solutions ( $\mathrm{pH} 4.8$ ).

Pretreatment Methods. Heated ammonia pretreatment was operated in following instructions. According to the solid liquid ratio as 1:10, the rice straw powders were mixed with ammonia of concentration of $5 \%, 10 \%$ and $25 \%$ in reaction kettles respectively. Mixtures were heated at $100^{\circ} \mathrm{C}$ for 2 hours and then 
leached. The residues were washed to neutral by water, and then dried and weighed. Combined pretreatment of heated ammonia and microwaves was operated in following instructions. According to the solid liquid ratio as 1:10, the rice straw powder was mixed with ammonia of concentration of $10 \%$ in reaction kettles. Mixtures was heated at $100^{\circ} \mathrm{C}$ for 2 hours in the microwave environment $(28 \mathrm{kHz} / 300 \mathrm{~W})$, then leached. The residue was washed to neutral by water, and then dried and weighed. $\mathrm{NaOH}$ pretreatment was operated in following instructions. According to the solid liquid ratio as 1:10, the rice straw powders were mixed with ammonia of concentration of $1 \%, 2 \%$ and $5 \%$ respectively in reaction kettles. Mixtures are heated at $100^{\circ} \mathrm{C}$ for 2 hours and then leached. The residues were washed to neutral by water, and then dried and weighed. Lime pretreatment was operated in following instructions. $1 \mathrm{~g}$ rice straw powders and $10 \mathrm{~mL}$ water were mixed with $0.05 \mathrm{~g}, 0.1 \mathrm{~g}, 0.2 \mathrm{~g}$ lime respectively in reaction kettles. Mixtures are heated at $100^{\circ} \mathrm{C}$ for 2 hours and then leached. The residues were washed to neutral by water, and then dried and weighed.

Enzyme assays. Carboxymethyl cellulase (CMCase) (20FPU/g) from and cellobiase from Aspergillus niger $(10 \mathrm{CBU} / \mathrm{g})$ were assayed in reaction mixture $(50 \mathrm{ml})$ with $80 \mathrm{~g} / \mathrm{L}$ substrate concentration and $\mathrm{pH} 5.0$. After $48 \mathrm{~h}$ incubation at $50^{\circ} \mathrm{C}$, the reducing sugar liberated in the reaction mixture was measured by the dinitrosalicylic acid (DNS) method [17].

\section{Results and Discussion}

Removal rate of main components and weight loss after pretreatment. Effects of different pretreatment technologies on rice straw were evaluated. $2 \% \mathrm{NaOH}$ changed the surface and inside structure of rice straw in the most remarkable way. The inside structure of straw was swelled fully, and the porosity of surface grew drastically. Thus, the availability of contact of cellulase and cellulose was increased largely (Figure.1 d) $[18,19]$. The straw pretreated by combined technology of ammonia and microwaves had more porous surface than that pretreated by ammonia only (Figure.1 a ,c ). That indicates microwave enhance the effect of pretreatment. Compared with other alkalis, the lime had less noticeable effect on the surface and inside structure of rice straw.

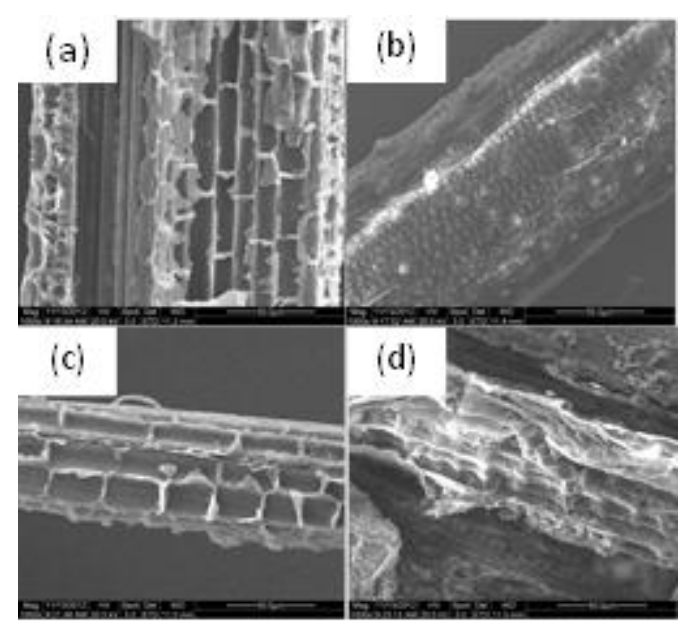

Figure.1 Electron micrographs of residues after different pretreatments (a) Combined pretreatment of heated ammonia and microwaves $\left(100^{\circ} \mathrm{C}, 10 \%\right)$; (b) Lime pretreatment $\left(100^{\circ} \mathrm{C}, 0.2 \mathrm{~g} / \mathrm{g}\right)$; (c) heated ammonia pretreatmen $\left(100^{\circ} \mathrm{C}, 10 \%\right)$; (d) $\mathrm{NaOH}$ pretreatment $\left(100^{\circ} \mathrm{C}, 2 \%\right)$

Heated ammonia pretreatment removed lignin effectively while left most hemicellulose and cellulose. Removal rates of lignin were $62.1 \%$ and $44.9 \%$, and removed rates of hemicellulose were $29.9 \%$ and $23.3 \%$ when straws were pretreated by heated $25 \%$ and $10 \%$ ammonia respectively. Furthermore, microwaves enhanced the removal of lignin and hemicellulose because that combined pretreatment of heated ammonia and microwaves had more $2.3 \%$ lignin removal and $5.5 \%$ hemicellulose removal additionally, compared with 
heated ammonia only. The weight losses were $27.3 \%$ and $24.6 \%$ when raw materials were pretreated by $25 \%$ and $10 \%$ heated ammonia respectively, while the combined pretreatment had a slightly higher weight loss as $25.1 \%$.

$\mathrm{NaOH}$ pretreatment removed both lignin and hemicellulose powerfully, while the loss of cellulose is rather high. The removal rates of lignin and hemicellulose increased when dose is raised. So did the weight loss of raw materials. $5 \% \mathrm{NaOH}$ pretreatment removed $91.5 \%$ lignin, $74.9 \%$ hemicellulose besides of $7.5 \%$ cellulose, however, weight loss achieved $49.6 \% .2 \%$ and $1 \% \mathrm{NaOH}$ pretreatments had $3.5 \%$ and $7.2 \%$ less removal rate of lignin than $5 \% \mathrm{NaOH}, 13.3 \%$ and $29.3 \%$ less removal rate of hemicellulose than $5 \% \mathrm{NaOH}$. But the weight losses of $2 \%$ and $1 \% \mathrm{NaOH}$ pretreatments were also less than $5 \% \mathrm{NaOH}$ as $3.6 \%$ and $9.5 \%$.

Lime pretreatment removed more lignin and hemicellulose when dose was increasing. But the loss of cellulose was raised evidently during the process. The removal rate of lignin and hemicellulose were $44.9 \%$ and $49.7 \%$ of $0.2 \mathrm{~g} / \mathrm{g}$ lime pretreatment, which was the best dosage in this research, while $14.5 \%$ cellulose was decomposed into solution and weight loss reached $33.8 \%$.

Analyzing and comparing different pretreatment technologies, it was found that $\mathrm{NaOH}$ pretreatment can remove more lignin and hemicellulose and keep more cellulose. Although the weight loss is rather high, it also related with the removal of lignin and hemicellulose closely. Non-specific binding of lignin and cellulase hinders the hydrolysis of cellulose, while hemicellulose decreases the accessibility of cellulase [20]. $\mathrm{NaOH}$ pretreatment with appropriate concentration can achieve not only rather ideal removal of lignin and hemicellulose but acceptable weight loss of raw material.

Analysis of enzymatic saccharification of different residues. 48-hours enzymatic saccharification of residues from different pretreatments technologies indicated that different alkalis and their doses impact on the enzymatic saccharification rate greatly. Residues from $\mathrm{NaOH}$ pretreatment contributed to much better saccharification effect (Figure.2) than those from ammonia and lime. 1\%, 2\% and 5\% $\mathrm{NaOH}$ pretreatment yielded $88.6 \%, 95.3 \%$ and $96.6 \%$ saccharification rates at last. Heated ammonia pretreatment did not work as well as $\mathrm{NaOH} .5 \%, 10 \%$ and $25 \%$ heated ammonia pretreatment yielded $48.7 \%, 70.1 \%$ and $72.5 \%$ saccharification rates eventually. The combination of microwaves and heated ammonia increased additional $1.8 \%$ saccharification rate compared with $10 \%$ heated ammonia pretreatment. Residues from lime pretreatment had their saccharification rates varied in a broad range, from $39.3 \%$ to $73.8 \%$. Although the largest dose of lime seemed promoting the saccharification of residue, it also took higher environmental risk[11].

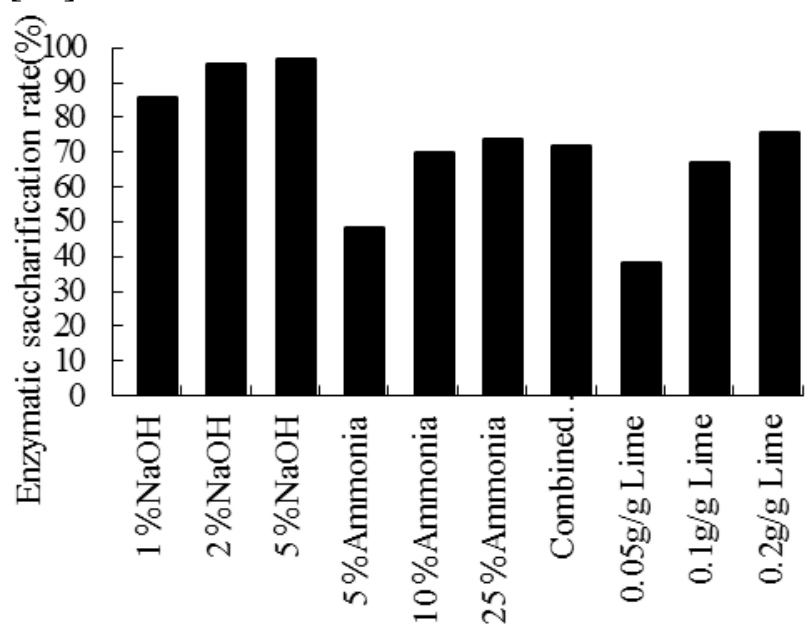

Fig.2 Enzymatic saccharification rates of residues from different pretreatment

There was a positive relationship between enzymatic saccharification rate and removal rate of lignin (Table 1and Figure 2). That probably results from that lignin blocks the sufficient contact of cellulase with cellulose substrate and then decreases the enzymatic effect [21,22]. Moreover, the efficient pretreatment technologies 
increased the surface porosity and water binding capacity of the raw materials by swelling that raised the efficiency of enzymatic saccharification too[23,24]

Table 1 Removal rates and weight loss of different pretreatment technologies

\begin{tabular}{ccccc}
\hline $\begin{array}{c}\text { Pretreatment } \\
\text { technology }\end{array}$ & \multicolumn{3}{c}{ Removal rate(\%) } & \begin{tabular}{c} 
Weight loss \\
\cline { 2 - 3 }$(\%)$
\end{tabular} \\
\hline $25 \%$ ammonia & 4.0 & 29.9 & 62.1 & 27.3 \\
$10 \%$ ammonia & 2.1 & 23.3 & 44.9 & 24.6 \\
$10 \%$ ammonia & 1.8 & 28.8 & 47.2 & 25.1 \\
$+\mathrm{Microwaves}$ & & & & \\
$5 \% \mathrm{NaOH}$ & 7.5 & 74.9 & 91.5 & 49.6 \\
$2 \% \mathrm{NaOH}$ & 5.8 & 61.6 & 88.0 & 46.0 \\
$1 \% \mathrm{NaOH}$ & 3.5 & 45.6 & 84.3 & 40.1 \\
$0.2 \mathrm{~g} / \mathrm{g}$ lime & 14.5 & 49.7 & 44.9 & 33.8 \\
\hline
\end{tabular}

\section{Conclusion}

Heated ammonia pretreatment was more effectively to remove lignin than hemicellulose. Because of remaining of hemicellulose, heated ammonia lost less weight of raw materials. Combination of microwaves and heated ammonia enhanced the removal of lignin and also raised enzymatic saccharification rate.

Besides of lignin and hemicellulose, lime pretreatment removed cellulose as well, that decreased the enzymatic saccharification finally.

$\mathrm{NaOH}$ removed lignin and hemicellulose in the most effective way. Furthermore, because of the loss of most lignin and hemicellulose, the enzymatic saccharification was enhanced as a result.. However, higher dose of $\mathrm{NaOH}$ brought a rather high weight loss of raw material. It is necessary to balance the removal rate and weight loss in this pretreatment.

Take enzymatic saccharification and weight loss into concern, $2 \% \mathrm{NaOH}$ pretreatment at $100^{\circ} \mathrm{C}$ is the most effective alkaline pretreatment technology of rice straw for ethanol production.

\section{Acknowledgements}

This research was supported by the Fundamental Research Funds for the Central Universities ( 2682014CX016), and Science and Technology Supporting Program of Sichuan Province (2015NZ0097)

\section{References}

[1] Lynd, LR, Laser, MS, Bransby, D, Dale, BE, Davison, B, Hamilton, R.. How biotech can transform biofuels. Nat Biotechnol 26 (2008)169-172

[2] Zhu, JY, Zhuang, XS. Conceptual net energy output for biofuel production from lignocellulosic biomass through biorefining. Prog Energy Combust Sci 38 (2012) 583-589

[3] Cherry J R and Fidantsef A L . Directed evolution of industrial enzymes: an update. Current Opinion in Biotechnology . 14 (2003) 438-443 
[4] Leu S.Y. , Zhu J. Y. Substrate-Related Factors Affecting Enzymatic Saccharification of Lignocelluloses: Our Recent Understanding . BioEnergy Research.6 (2013) 405-415

[5] Balat M, Balat H, Oz C. Progress in bioethanol processing. Prog Energ Combust. 34 (2008) 551-73.

[6]. Lee I, Evans BR, Woodward J. The mechanism of cellulase action on cotton fibers: evidence from atomic force microscopy. Ultramicroscopy. 82 (2000) 213-21.

[7] Gregg DJ, Saddler JN. Factors affecting cellulose hydrolysis and the potential of enzyme recycle to enhance the efficiency of an integrated wood to ethanol process. Biotechnol Bioeng. 51 (1996) 375-83.

[8] Gao R.F., Zhang J.G. Effect of fermention on ethanol production from fresh sweet corn stalks. Acta Prataculturae Sinica.23 (2014) 154-159

[9] Zhao, X, Zhang, L, Liu, D. Biomass recalcitrance. Part I: the chemical compositions and physical structures affecting the enzymatic hydrolysis of lignocellulose. Biofuels, Bioprod Biorefin 6 (2012) 465-482 [10] Eizawawy W.K, Ibrahim M.M., Abdel F.Y.R. Acid and enzymehydrolysis toconvert pretreated lignocellulosic materials in to glucose for ethanol production. Carbohydrate Polymers, 84 (2011) 865-871

[11] Wang, ZJ, Zhu, JY, Gleisner, R, Chen, KF. 2012. Ethanol production form poplar wood the rough enzymatic saccharification and fermentation by dilute acid and SPORL pretreatments. Fuel 95: 606-614

[12] Fan C., Qiu Z.P., Hua J.J. Research Progress of Ethanol Production from the Fermentation of Agricultural Wastes. Journal of Anhui Agricultural Sciences. 32 (2011) 19961-4

[13] Purwadi R, Niklasson C, Taherzadeh MJ. 2004 Kinetic study of detoxificationof dilute-acid hydrolyzates by $\mathrm{Ca}(\mathrm{OH}) 2$. J Biotechnol. 114:187-98

[14] Saha BC. Hemicellulose bioconversion. J Ind Microbiol Biotechnol, 30 (2003) 279-91

[15] Vidal, BC, Dien, BS, Ting, KC, Singh, V. Influence of feedstock particle size on lignocellulose conversion - a review. Appl Biochem Biotechnol 164 (2011) 1405-1421

[16] Miller GL. Use of dinitrosalicylic acid reagent for determination of reducing sugar. Anal Chem.31(1999) 426-8.

[17] Studer, MH, DeMartini, JD, Davis, MF, et al. Lignin content in natural Populus variants affects sugar release. Proc Natl Acad Sci (PNAS) 108 (2011) 6300-6305

[18] Nakagame, S, Chandra, RP, Kadla, JF, Saddler, JN. Enhancing the enzymatic hydrolysis of lignocellulosic biomass by increasing the carboxylic acid content of the associated lignin. Biotechnol Bioeng 108 (2011) 538-548

[19] Hall, M, Bansal, P, Lee, JH, Realff, MJ, Bommarius, AS . Cellulose crystallinity — a key predictor of the enzymatic hydrolysis rate. FEBS J 277 (2010) 1571-1582

[20] Yukiko S,Hiroko K K. Ethanol production from ensiled rice straw and whole-crop silage by the simultaneous enzymatic saccharification and fermentation process.Bioscience and Bioengineering. 3 (2011) 320-325.

[21] Ballesteros M,Oliva J M,Negro M J. Ethanol from lignocellulosic materials by a simultaneous saccharification and fermentation process (SFS) with Kluyveromyces marxianus CECT 10875.Process Biochemistry.12 (2004) 1843-1848.

[22] Cardona C, Quintero J, Paz I. Production of bioethanol from sugarcane bagasse: status and perspectives. Bioresource Technology. 101 (2010) 4754-66.

[23] Klinke HB, Olsson LK, Thomsen AB, Ahring BK. Potential inhibitors from wet oxidation of wheat straw and their effect on ethanol production by Saccharomyces cerevisiae: wet oxidation and fermentation by yeast. Biotechnol Bioeng .81 (2003) 738-47.

[24] Moxley, G, Gaspar, AR, Higgins, D, Xu, H. Structural changes of corn stover lignin during acid pretreatment. J Ind Microbiol Biotechnol .39 (2012) 1289-1299 